\title{
WORD OF MOUTH PADA MEREK PLANET BAN
}

\author{
Oleh: \\ Renaldi Akbar \\ Egi Arvian Firmansyah ${ }^{2}$ \\ Universitas Padjadjaran \\ Email: \\ egi.firmansyah@unpad.ac.id
}

\begin{abstract}
ABSTRAK
Sepeda motor merupakan kendaraan yang diminati oleh sebagian besar orang di Indonesia dalam menjalankan mobilitas sehari-hari baik itu untuk bekerja, berlibur, sekolah dan untuk melakukan aktifitas usaha. Hal ini merupakan peluang yang dimanfaatkan oleh pengusaha-pengusaha yang berkaitan dengan sepeda motor seperti halnya produsen ban. Mereka dituntut untuk mengeluarkan produkproduk yang berkualitas sehingga dapat menarik minat masyarakat untuk menggunakan produknya. Penelitian ini bertujuan untuk mengetahui tingkat word of mouth pada salah satu penjual ban motor berkualitas, yaitu Planet Ban cabang Mohammad Toha Kota Bandung. Penelitian ini termasuk ke dalam penelitian deskriptif yang menggambarkan hasil penelitian dari data yang diamati. Sampel yang digunakan dalam penelitian ini sebanyak 100 responden yang merupakan konsumen Planet Ban. Pengumpulan data dalam penelitian ini dilakukan menggunakan kuesioner offline dimana konsumen ditanya langsung ketika mengganti ban sepeda motornya di Planet Ban. Hasil kuisioner kemudian diolah, dihitung dan hasilnya disajikan mengikuti garis kontinum untuk mengetahui keadaan atau tingkat word of mouth. Hasil penelitian menunjukan bahwa word of mouth secara keseluruhan dinilai cukup berjalan baik dengan rata-rata skor 67,12 persen. Hal ini menunjukan bahwa Planet Ban Cabang Moh. Toha Kota Bandung mampu memberikan citra yang baik dimata konsumen sehingga konsumen tergerak untuk melakukan word of mouth. Penelitian selanjutnya sebaiknya menggunakan metode kuantitatif untuk memperdalam hasil dari penelitian.
\end{abstract}

Kata Kunci: Word of mouth, Planet Ban

\section{A. PENDAHULUAN}

Dalam menentukan kesuksesan suatu perusahaan, perusahaan harus pintar dalam memahami perilaku konsumen pada pasar sasarannya. PT. Surganya Motor Indonesia (Planet Ban) adalah sebuah perusahaan yang berdiri sebagai pelopor toko penjualan yang khusus menjual ban kendaraan roda dua. Di era persaingan 
bisnis ini, Planet Ban dituntut untuk memiliki competitive advantage sehingga perusahaan dapat bersaing dengan perusahaan lain yang sejenis. Planet Ban fokus menjual ban kendaraan roda dua dan selalu menjual ban yang fresh karena tidak menyimpan ban dalam waktu yang lama. Planet Ban memiliki keunggulan dibandingkan dengan toko ban yang lain karena gerainya yang tersebar banyak 400 toko ban di seluruh Indonesia, sehingga memudahkan kosumen dalam mencari Planet Ban terdekat.

Ketika seorang pelanggan yang telah berkunjung ke sebuah tempat atau menggunakan sebuah produk, maka pelanggan tersebut akan memberitahukan pengalamannya tersebut kepada orang terdekatnya. Word of mouth dapat berakibat positif atau negatif bagi perusahaan (Dasgupta \& Mathew, 2012). Jika pelanggan merasakan pengalaman atau mendapatkan kesan yang baik(Chookaew, chanin, Charatarawat, Sriprasert, \& Nimpaya, 2015), maka ia akan melakukan proses word of mouth daninformasi yang disampaikan berisi informasi yang positif.Begitupun sebaliknya, jika pelanggan tersebut merasakan pengalaman yang buruk, maka word of mouth yang disampaikan berisi informasi yang negatif.

Word of mouth dapat menjadi salah satu sumber bagi konsumen untuk mengujungi suatu tempat (Ezeuduji, November, \& Haupt, 2016). Walau pun word of mouth dianggap tidak memiliki pengaruh terhadap keputusan pembelian konsumen (Rinandiyana, Kurniawati, \& Kurniawan, 2017), perusahaan perlu memperhatikan hal ini karena konsumen yang marah atau kecewa akan membuat minat mereka untuk membeli kembali menjadi rendah (Iqbal \& Hassan, 2017). Berdasarkan latar belakang di atas, penelitian ini bertujuan untuk menggambarkan kondisi word of mouth yang terjadidi Planet Ban Cabang Moh Toha Kota Bandung.

\section{B. KAJIAN PUSTAKA}

Word of mouth merupakansalah satu iklan gratis bagi perusahaan dan menurut penelitian Nielsen, 92\% konsumen lebih mempercayai saran dari keluarga dan teman dari pada iklan (Mosley, 2017; Whitler, 2014). Word of mouth memberikan kesempatan kepada konsumen untuk membicarakan produk perusahaan dan membuat percakapan itu menjadi mudah untuk dilakukan (Sernovitz, 2012). Word of mouth marketing adalah spesialisasi baru yang dapat ditindaklanjuti, dilacak, dan direncanakan sebagai bentuk lain dari marketing.

Sernovitz (2012) membagi word of mouth menjadi lima elemen yang dibutuhkan marketer agar word of mouth tersebar, yaitu talkers, topics, tools, taking part, dan tracking.

Penelitian telah banyak dilakukan oleh para peneliti terkait pengaruh word of mouth terhadap keputusan pembelian (Rahayu, 2014; Nughraha, 2015; Listiyanidan Oktaria, 2013; Lotulung, Lapian, dan Moniharapon, 2015; Febyanto dan Hanggih, 2015; Basri et. al, 2016). Namun, penelitian ini fokus hanya pada satu variabel yaitu word of mouth terhadap salah satu merek toko ban di Kota Bandung. Hal ini diharapkan dapat memberikan gambaran lebih utuh mengenai praktik word of mouth itu sendiri. 


\section{METODE PENELITIAN}

Penelitian mengenai word of mouth ini menggunakan teknik pengumpulan data penelitian deskriptif, yaitu penelitian yang memberikan gambaran mengenai word of mouth di Planet Ban cabang Moh Toha Kota Bandung.Variabel word of mouth marketing dalam penelitian ini terdiri dari dimensi berikut ini, yaitu talkers (pembicara), topics (topik), tools (alat), taking part (partisipasi), dan tracking (pengawasan).

Pengumpulan data dilakukan yaitu dengan cara menyebarkan kuesioner. Kuesioner terdiri dari dua bagian yaitu profil responden dan jawaban responden terkait pertanyaan word of mouth. Analisis data dalam penelitian ini menggunakan teknik deskriptif. Operasional variabel yang digunakan menjadi tolak ukur dalam membuat kuesioner. Berikut operasional variabel yang digunakan:

Tabel 1. Variabel Penelitian

\begin{tabular}{|c|c|c|c|c|}
\hline VARIABEL & DIMENSI & INDIKATOR & $\begin{array}{c}\text { NOMOR } \\
\text { ITEM }\end{array}$ & SKALA \\
\hline \multicolumn{5}{|l|}{ Word of Mouth } \\
\hline $\begin{array}{l}\text { Sumber: } \\
\text { Sernovitz } \\
(2012: 19)\end{array}$ & Talkers & $\begin{array}{l}\text { 1. Memiliki hubungan satu sama lain } \\
\text { 2. Informasi dapat dipercaya } \\
\text { 3. Penyampaian informasi jelas }\end{array}$ & $1-3$ & Ordinal \\
\hline$\sim$ & Topics & $\begin{array}{l}\text { 1. Memiliki harga yang kompetitif } \\
\text { 2. Memiliki produk yang beragam } \\
\text { 3. Memiliki kualitas yang baik } \\
\text { 4. Memiliki layanan yang baik }\end{array}$ & $4-7$ & Ordinal \\
\hline$\sim$ & Tools & $\begin{array}{l}\text { 1. Penyampaian informasi dilakukan } \\
\text { melalui media social } \\
\text { 2. Penyampaian informasi dilakukan } \\
\text { saat berkumpul }\end{array}$ & $8-9$ & Ordinal \\
\hline$\sim$ & $\begin{array}{c}\text { Taking } \\
\text { Part }\end{array}$ & $\begin{array}{l}\text { 1. Memberikan komentar dan } \\
\text { menceritakan hal-hal positif } \\
\text { 2. Menjawab pertanyaan maupun } \\
\text { keluhan dengan baik }\end{array}$ & $10-11$ & Ordinal \\
\hline$\sim$ & Tracking & $\begin{array}{l}\text { 1. Tersedianya media untuk } \\
\text { memberikan masukan, kritik, atau } \\
\text { saran dari konsumen di media social } \\
\text { 2. Kemampuan menanggapi kritik dan } \\
\text { saran }\end{array}$ & $12-13$ & Ordinal \\
\hline
\end{tabular}

\section{Skala Pengukuran}

Data pengukuran yang digunakan dalam penelitian ini adalah ordinal dengan skala Likert. Agar tidak terjadi pemusatan data dimana responden lebih 
memilih netral, maka penulis menggunakan lima jawaban, yaitu Sangat Setuju (5), Setuju (4), Netral (3), Tidak Setuju (2), dan Sangat Tidak Setuju (1).

Teknik sampel yang digunakan dalam penelitian ini adalah non probability sampling. Jumlah populasi dari konsumen Planet Ban Cabang Moh Toha Kota Bandung yang pernah melakukan transaksi jumlahnya tidak diketahui, karena jumlah populasi dalam penelitian ini tidak diketahui dengan pasti, maka ukuran sampel ditentukan dengan menggunakan teknik Slovin. Berdasarkan data pemilik kendaraan roda dua Jawa Barat Kota Bandung III Soetta per tahun 2016, pemilik kendaraan roda dua sebanyak 355.560 orang. Maka sampel yang akan digunakan sebanyak

$$
\begin{gathered}
n=\frac{355.650}{1+355.650 \times 0,1^{2}} \\
\mathbf{n}=\mathbf{9 9 . 9 7}
\end{gathered}
$$

Sehingga sampel minimum pada penelitian ini adalah 99.97 responden, tetap untuk mengurangi kesalahan pengisian kuisioner, penulis membulatkannya menjadi 100 responden.

Pengumpulan data yang digunakan oleh penulis adalah menggunakan kuesioner dan studi kepustakaan. Teknik pengolahan data dalam penelitian ini adalah data yang diperoleh dari hasil penyebaran kuisioner kepada 100 responden. Pada penelitian ini, kami menggunakan kuisioner yang masing-masing pertanyaan disertai dengan lima kemungkinan jawaban yang harus dipilih oleh responden.

\section{HASIL DAN PEMBAHASAN}

\section{Karakteristik Responden}

Dalam penelitian ini dikumpulkan data primer untuk menganalisis Word of Mouth kepada 100 responden yang menjadi sampel penelitian. Data karakteristik responden dalam penelitian ini sangat dibutuhkan untuk mengetahui latar belakang responden yang menjadi konsumen pada Planet Ban Cabang Moh Toha Kota Bandung.

Tabel 2. Profil Responden

\begin{tabular}{llcc}
\hline No & \multicolumn{1}{c}{ Item } & Frekuensi & Persentase \\
\hline 1 & Jenis Kelamin & & \\
& Pria & 80 & $80 \%$ \\
& Wanita & 20 & $20 \%$ \\
2 & Usia & 17 & $17 \%$ \\
& $<18$ tahun & 43 & $43 \%$ \\
& 19-25 tahun & 40 & $40 \%$ \\
& $>$ 25 tahun & & \\
& Penghasilan per bulan (rupiah) & 38 & $38 \%$ \\
& 1.000.000-3.000.000 & 42 & $42 \%$ \\
& 3.000.001 - 5.000.000 & 14 & $14 \%$ \\
& 5.000.001 - 10.000.000 & 6 & $6 \%$ \\
& $>10.000 .000$ & & \\
& Status pekerjaan & 37 & $37 \%$ \\
\hline
\end{tabular}




\begin{tabular}{|c|c|c|c|}
\hline \multirow{7}{*}{5} & Pegawai negeri & 22 & $22 \%$ \\
\hline & Mahasiswa & 21 & $21 \%$ \\
\hline & Lain-lain & 10 & $10 \%$ \\
\hline & Sudah mengunjungi berapa kali & & \\
\hline & 1 kali & 50 & $50 \%$ \\
\hline & $2-3$ kali & 34 & $34 \%$ \\
\hline & $>3$ kali & 16 & $16 \%$ \\
\hline
\end{tabular}

Berdasarkan tabel 2, dapat dilihat bahwa $80 \%$ responden merupakan berjenis kelamin pria dan sisanya sebesar $20 \%$ berjenis kelamin wanita. Berdasarkan hasil ini, diketahui bahwa lebih pria lebih dominan menjadi konsumen Planet Ban Cabang Moh Toha Kota Bandung.

Berdasarkan usianya, 17\% responden berusia kurang dari 18 tahun, $43 \%$ responden berusia 19-25 tahun, dan 40\% responden berusia lebih dari 25 tahun. Dari hasil ini diketahui bahwa mayoritas konsumen adalah kaum milenial yang sudah bekerja. Data ini didukung pertama oleh data penghasilan dimana mayoritas responden $(42 \%)$ memiliki penghasilan bulanan sebesar Rp. 3.000.001 - Rp. 5.000.000. Kedua, data status pekerjaan juga menunjukan bahwa mayoritas responden $(37 \%)$ adalah para pekerja swasta.

Berdasarkan frekuensi kunjungan responden, 50\% responden mengunjungi Planet Ban Cabang Moh Toha Kota Bandung sebanyak satu kali atau pertama kalinya saat kami wawancara.Sedangkan 34\% responden pernah mengunjungi Planet Ban Cabang Moh Toha Kota Bandung sebanyak 2-3 kali, dan 16\% responden mengunjungi Planet Ban Cabang Moh Toha Kota Bandung lebih dari 3 kali. Responden terbanyak adalah responden yang berkunjung ke Planet Ban Cabang Moh Toha Kota Bandung sebanyak satu kali yang berarti Planet Ban Cabang Moh Toha Kota Bandung mempunyai banyak pengunjung baru. Dengan demikian, akan sangat penting bagi perusahaan untuk menjaga layanan sehingga menimbulkan loyalitas pelanggan dalam jangka panjang.

\section{Tanggapan Responden mengenai Word of Mouth}

Dari hasil pengolahan data tentang variabel Word of Mouth yang diukur dengan empat belas pernyataan, dapat diuraikan sebagai berikut:

1) Saya memiliki kenalan dekat yang juga konsumen Planet Ban Cabang Moh Toha Kota Bandung.

Tanggapan responden terhadap kepemilikan kenalan dekat yang juga konsumen Planet Ban Cabang Moh Toha Kota Bandung termasuk dalam kategori baik dengan persentase $73.8 \%$. Hal ini menunjukan konsumen yang satu dengan yang lainnya memiliki hubungan yang cukup baik.

2) Saya pernah melakukan diskusi tentang Planet Ban Cabang Moh Toha Kota Bandung kepada orang lain dalam 1 bulan terakhir.

Tanggapan responden terhadap pengalaman responden mendiskusikan pengalamannya mengganti ban di Planet Ban Cabang Moh Toha Kota Bandung termasuk dalam kategori cukup baik dengan persentase $60.8 \%$. 
Hal ini menunjukan konsumen Planet Ban Cabang Moh Toha Kota Bandung pernah membicarakan pengalamannya dengan sesama konsumen.

3) Saya memberikan informasi yang jelas tentang Planet ban Cabang Moh Toha Kota Bandung kepada orang lain.

Tanggapan responden terhadap pengalaman responden memberikan informasi yang jelas terhadap orang lain termasuk kedalam kategori cukup baik dengan persentase $65.8 \%$. Hal ini menunjukan konsumen Planet Ban Cabang Moh Toha Kota Bandung memberikan informasi yang jelas kepada orang lain.

4) Saya memberikan informasi tentang harga produk Planet Ban Cabang Moh Toha Kota Bandung yang relative terjangkau.

Tanggapan responden terhadap pengalaman responden memberikan informasi tentang harga yang relatif terjangkau termasuk kedalam kategori baik dengan persentase $73.4 \%$. Hal ini menunjukan perusahaan sudah baik dalam menentukan harga yang dapat terjangkau bagi konsumen.

5) Saya memberikan informasi tentang produk Planet Ban Cabang Moh Toha Kota Bandung yang beragam.

Tanggapan konsumen terhadap pengalaman responden memberikan informasi tentang produk Planet Ban Cabang Moh Toha Kota Bandung yang beragam termasuk kedalam kategori cukup baik dengan persentase 65.8\%. Ini menunjukan konsumen Planet Ban Cabang Moh Toha Kota Bandung memberikan informasi yang jelas kepada orang lain.

6) Saya memberikan informasi tentang pelayanan Planet Ban Cabang Moh Toha Kota Bandung yang baik.

Tanggapan responden terhadap pengalaman responden memberikan informasi tentang pelayanan Planet Ban Cabang Moh Toha Kota Bandung kepada orang lain termasuk dalam kategori baik dengan persentase $71.4 \%$. Ini menunjukan konsumen dalam memberikan informasi tentang pelayanan Planet Ban Cabang Moh Toha Kota Bandung sudah baik.

7) Saya memberikan informasi tentang produk Planet Ban Cabang Moh Toha Kota Bandung yang berkualitas baik.

Tanggapan responden terhadap pengalaman memberikan informasi tentang produk Planet Ban Cabang Moh Toha Kota Bandung yang berkualitas baik kepada orang lain termasuk kedalam kategori baik dengan persentase 74.4\%. Hal ini menunjukan konsumen sudah cukup baik dalam memberikan informasi tentang produk Planet Ban Cabang Moh Toha Kota Bandung yang berkualitas baik.

8) Saya membagikan pengalaman tentang Planet Ban Cabang Moh Toha Kota Bandung pada media sosial.

Tanggapan responden terhadap pengalaman responden membagikan pengalaman mengunjungi Planet Ban Cabang Moh Toha Kota Bandung pada media sosial termasuk kedalam kategori kurang dengan persentase $54.8 \%$. Media sosial yang banyak digunakan oleh responden adalah 
Facebook dan Instagram. Ini menunjukan konsumen Planet ban Cabang Moh Toha Kota Bandung tidak selalu membagikan pengalamannya pada media sosial.

9) Saya pernah membicarakan tentang Planet Ban Cabang Moh Toha Kota Bandung kepada komunitas motor.

Tanggapan responden terhadap pengalaman responden membicarakan pengalaman tentang Planet Ban Cabang Moh Toha Kota Bandung pada komunitas motor termasuk kedalam kategori cukup dengan persentase $60.2 \%$. Hal ini menunjukan tidak semua konsumen pernah membicarakan Planet Ban Cabang Moh Toha Kota Bandung kepada komunitas motor.

10) Saya pernah membicarakan tentang kelebihan Planet Ban Cabang Moh Toha Kota Bandung kepada orang lain.

Tanggapan responden terhadap pengalaman responden membicarakan kelebihan Planet ban Cabang Moh Toha Kota Bandung pada orang lain termasuk kedalam kategori baik dengan persentase 69.2\%. Hal ini menunjukan konsumen Planet Ban cabang Moh Toha Kota Bandung sering membicarakan kelebihan Planet Ban Moh Toha Kota Bandung.

11) Saya memberi informasi kepada orang lain bahwa Planet Ban Cabang Moh Toha Kota Bandung menjawab keluhan dengan baik.

Tanggapan responden terhadap pengalaman responden memberi informasi kepada orang lain bahwa Planet Ban Cabang Moh Toha Kota Bandung menjawab keluhan dengan baik termasuk kedalam kategori baik dengan persentase $69.8 \%$. Hal ini menunjukan bahwa konsumen Planet Ban Cabang Moh Toha Kota Bandung saling memberikan informasi kepada orang lain bahwa Planet Ban Cabang Moh Toha Kota Bandung dapat menjawab keluhan dengan baik.

12) Saya memberi informasi kepada orang lain bahwa Planet Ban Cabang Moh Toha Kota Bandung menyediakan sarana untuk memberikan kritik dan saran.

Tanggapan responden terhadap pengalaman responden memberi informasi kepada orang lain bahwa Planet Ban Cabang Moh Toha Kota Bandung menyediakan sarana untuk memberikan kritik dan saran termasuk ke dalam kategori cukup baik dengan persentase 66.8\%. Hal ini menunjukan konsumen Planet Ban Cabang Moh Toha Kota Bandung cukup baik dalam membagikan informasi bahwa Planet Ban Cabang Moh Toha Kota Bandung menyediakan sarana untuk memberikan kritik dan saran cukup baik.

13) Saya memberi informasi kepada orang lain bahwa Planet Ban Cabang Moh Toha Kota Bandung mampu untuk menanggapi kritik dan saran pelanggan.

Tanggapan responden terhadap pengalaman responden memberi informasi kepada orang lain bahwa Planet Ban Cabang Moh Toha Kota Bandung menyediakan sarana untuk menanggapi kritik dan saran termasuk kedalam kategori cukup baik dengan persentase $65.6 \%$. Hal ini menunjukan bahwa konsumen Planet Ban Cabang Moh Toha Kota Bandung dalam membagikan 
informasi bahwa Planet Ban Cabang Moh Toha Kota Bamdung menyediakan sarana untuk menanggapi kritik dan saran cukup baik.

\section{4) Planet Ban Cabang Moh Toha Kota Bandung melakukan pemantauan pada konsumen.}

Tanggapan responden terhadap pengalaman responden memberi informasi kepada orang lain bahwa Planet Ban Cabang Moh Toha Kota Bandung melakukan pemantauan pada konsumen termasuk kedalam kategori cukup baik dengan persentase $67.8 \%$. Hal ini menunjukan pemantauan yang Planet Ban Cabang Moh Toha Kota Bandung sudah cukup baik.

Berdasarkan Hasil pengolahan, dapat dilihat bahwa skor total untuk variabel Word of Mouth adalah 4.698 dengan persentase 67.12\%. Jumlah skor tersebut jika dimasukkan ke dalam garis kontinum adalah sebagai berikut:

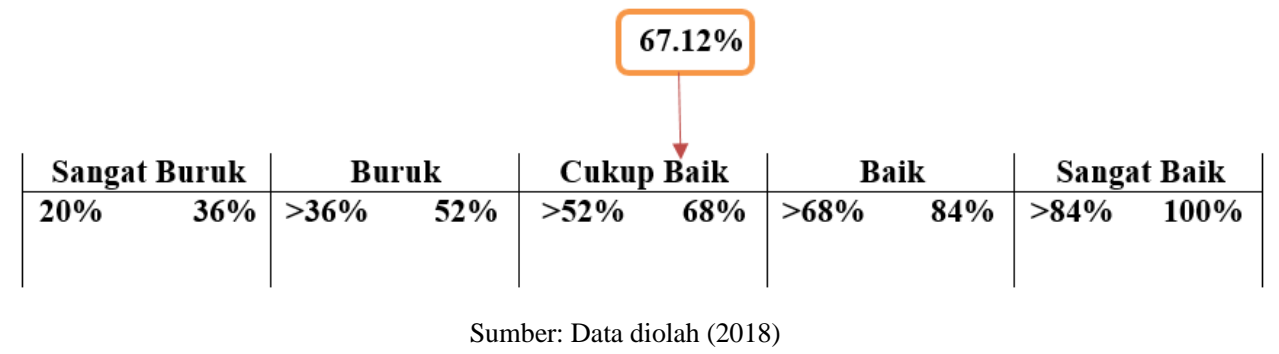

Gambar 1. Garis kontinum

\section{Analisis Hasil Penelitian dan Pembahasan}

Berdasarkan hasil dari analisi deskriptif, diketahui bahwa tanggapan responden mengenai word of mouth pada Planet Ban Cabang Moh Toha Kota Bandung memperoleh skor $67.12 \%$ dan dapat dikategorikan cukup baik. Artinya, tanggapan responden mengenai word of mouth terhadap objek penelitian memberikan pengaruh yang cukup baik.

Pada kuesioner penelitian terdapat 14 pernyataan mengenai word of mouth. Dari 14 pernyataan tersebut terdapat butir yang mempunyai skor paling besar yaitu skor nomor 7 mengenai tanggapan responden terkait pengalamannya untuk memberikan informasi tentang produk Planet Ban Cabang Moh Toha Kota Bandung yang berkualitas baik kepada orang lain. Kualitas merupakan aspek penting yang membuat konsumen memiliki kesediaan untuk melakukan word of mouth. Hasil ini seiring dengan penelitian sebelumnya yang menyatakan bahwa kualitas dari suatu produk memiliki hubungan dengan praktek word of mouth (Leonnard \& Thung, 2017; Susilowati \& Sugandini, 2018). Hal ini diperkuat oleh Sernovitz (2012:3) yang mengemukakan bahwa orang-orang atau konsumen akan membicarakan produk perusahaan dan membuat percakapan itu menjadi mudah untuk dilakukan.

Namun terdapat pernyataan dengan skor terendah yaitu pada skor nomor 8 mengenai tanggapan responden terhadap pengalaman responden membagikan pengalaman mengunjungi Planet Ban Cabang Moh Toha Kota Bandung di media sosial masuk ke dalam kategori kurang. Hal ini mengindikasikan bahwa para 
konsumen masih merasa enggan unutk membagi pengalaman di Planet Ban secara daring di media sosial mereka. Padahal, penilaian atau review konsumen secara daring dapat mempengaruhi kualitas dari word of mouth (Kim \& Song, 2010). Dengan demikian, perusahaan Planet Ban sebaiknya berupaya untuk men-trigger konsumennya untuk melakukan online review di media sosial atau saluran Internet lainnya.

\section{E. SIMPULAN}

Berdasarkan hasil penelitian dan pembahasan yang dilakukan terkait word of mouth di Planet Ban Cabang Moh Toha Kota Bandung, dapat disimpulkan bahwa word of mouth secara keseluruhan dinilai cukup baik dengan rata-rata skor 67,12\%. Hal ini menunjukan bahwa Planet Ban Cabang Moh Toha Kota Bandung mampu memberikan citra yang baik dimata konsumen. Butir tertinggi pada variabel word of mouth terkait aspek kualitas. Penelitian ini hanya terbatas pada wordof mouth di Planet Ban Cabang Moh Toha Kota Bandung. Penelitian selanjutnya sebaiknya dapat meneliti faktor-faktor lain seperti word of mouth elektronik (E-WoM), brand image, service quality, dan bauran pemasaran sehingga diharapkan dapat menyajikan hasil yang lebih sesuai. 


\section{DAFTAR PUSTAKA}

Basri, N. H., Ahmad, R., Anuar, F., \& Ismail, K. A. (2016). Effect of Word of Mouth Communication on Consumer Purchase Decision : Malay Upscale Restaurant. Asian Journal of Quality of Life Vol 1, Vol 222, Pages 324-331.

Chookaew, S., chanin, O., Charatarawat, J., Sriprasert, P., \& Nimpaya, S. (2015). Increasing Halal Tourism Potential at Andaman Gulf in Thailand for Muslim Country. Journal of Economics, Business and Management, 3(7), 739-741. https://doi.org/10.7763/JOEBM.2015.V3.277

Dasgupta, P., \& Mathew, J. Social media marketing at Reebok India - the dilemma of ROMI and beyond, 2 Emerald Emerging Markets Case Studies 1-19 (2012). https://doi.org/10.1108/20450621211291851

Ezeuduji, I. O., November, K. L., \& Haupt, C. (2016). Tourist Profile and Destination Brand Perception: The Case of Cape Town, South Africa. AUD Economica, 12(4), 115-132. Retrieved from http://journals.univdanubius.ro/index.php/oeconomica/article/viewFile/3310/3449

Febyanto, H. (2015). Komunikasi Word of Mouth dan Keputusan Pembelian (Studi Eksplanasi Pengaruh Word of Mouth Terhadap Keputusan Pembelian Produk Kaos Ngartun di Kota Yogyakarta. e-journal uajy, 1-13.

Iqbal, Q., \& Hassan, S. H. (2017). A Dyadic Analysis of Salespersons and Customers in Banking Sector: Humor Usage, Word of Mouth and Expectation of Continuity. International Academic Journal of Business Management, 5(3), 109-120.

Kim, H., \& Song, J. (2010). The quality of word-of-mouth in the online shopping mall. Journal of Research in Interactive Marketing, 4(4), 376-390. https://doi.org/10.1108/17505931011092844

Leonnard, \& Thung, F. (2017). The relationship of service quality, word-ofmouth, and repurchase intention in online transportation services. Journal of Process Management. New Technologies, 5(4), 30-40. https://doi.org/10.5937/jouproman5-15210

Listiyani, Y., \& Oktaria, V. (2013). Pengaruh Produk, Kualitas Layanan dan Word Of Mouth Terhadap Keputusan Pembelian di De Boliva Signature Sutos. Jurnal Hospitality dan Manajemen Jasa, Vol 1, No 2.

Lotulung, S. C., Lapian, J., \& Moniharapon, S. (2015). Pengaruh Kualitas Produk, Harga, dan WoM Terhadap Keputusan Pembelian Handphone Evercross Pada CV. Tristar Jaya Globalindo Manado. Jurnal Emba : Jurnal Riset Ekonomi, Manajemen, Bisnis, Akuntansi, Vol 3, No 3.

Mosley, M. (2017). Why is Word of Mouth Marketing so Important? | Social Media Today. Retrieved June 27, 2019, from 
https://www.socialmediatoday.com/marketing/why-word-mouth-marketingso-important

Nughraha, F. A. (2015). Pengaruh Word Of Mouth Terhadap Keputusan Pembelian dan Kepuasan Konsumen (Studi pada konsumen Kober Mie Setan Jalan Simpang Soekarno Hatta Nomor 1-2 Malang). Jurnal Administrasi Bisnis, Vol 22, No 1.

Rahayu, P. (2014). Pengaruh Word of Mouth Terhadap Keputusan Pembelian Konsumen Produk Smartfren Andromax (Studi pada mahasiswa kampus Ketintang Universitas Negeri Surabaya). Jurnal Pendidikan Tata Niaga, Vol 2, No 1.

Rinandiyana, L. R., Kurniawati, A., \& Kurniawan, D. (2017). Analisis FaktorFaktor Yang Mempengaruhi Keputusan Pembelian Oleh Generasi Milenial Pada Industri Kuliner Di Kota Tasikmalaya. Jurnal Ekonomi Manajemen, 3(1), 18-27.

Sernovitz, A. (2012). Word of Mouth Marketing How Smart Companies Get People Talking. Austin, Texas: Greenleaf Book Group Press.Chookaew, S., chanin, O., Charatarawat, J., Sriprasert, P., \& Nimpaya, S. (2015). Increasing Halal Tourism Potential at Andaman Gulf in Thailand for Muslim Country. Journal of Economics, Business and Management, 3(7), 739-741. https://doi.org/10.7763/JOEBM.2015.V3.277

Susilowati, C., \& Sugandini, D. (2018). Perceived Value, eWord-of-Mouth, Traditional Word- of-Mouth, and Perceived Quality to Destination Image of Vacation Tourists. Review of Integrative Business and Economics Research, $7(1), 312-321$.

Whitler, K. A. (2014). Why Word Of Mouth Marketing Is The Most Important Social Media. Retrieved June 27, 2019, from https://www.forbes.com/sites/kimberlywhitler/2014/07/17/why-word-ofmouth-marketing-is-the-most-important-social-media/\#67b17e8754a8 